\title{
Aspectos tradutórios do letramento: ressonâncias rítmicas ${ }^{1}$ \\ Translation aspects in literacy, and their rhythmic resonances
}

\author{
Maria Sílvia Cintra Martins ${ }^{2}$ \\ Universidade Federal de São Carlos, UFSCar - São Carlos - São Paulo, Brasil
}

\section{RESUMO}

De forma aplicada, este trabalho apresenta reflexões na interface entre os Estudos de Letramento e os Estudos de Tradução. O principal objetivo reside na discussão em torno do conceito de ritmo e de sua pertinência para os Estudos do Letramento. Ritmo e escritura, conceitos convencionalmente enfocados nos Estudos Literários, são trazidos para enriquecer questões próprias à Linguística Aplicada, de forma a dar conta de aspectos processuais inerentes à transição de uma a outra modalidade de linguagem. Defende-se que disciplinas universitárias voltadas à prática da escrita acadêmica levem em consideração, também, a prática da escrita em outros gêneros do discurso, incluindo-se o gênero literário, de forma a que se compreendam, de forma crítica, as transições/traduções necessárias em cada caso.

Palavras-chave: ritmo; gênero do discurso; oralidade; processo.

1. Trata-se de um dos resultados do Projeto FAPESP 2015/24353-5 "Percursos da tradução entre textos verbais e não verbais", em que amplio questões esboçadas em Martins (2011b).

2. Professora Associada do Departamento de Letras da UFSCar com atuação no PPGL/ UFSCar e no TRADUSP. Líder do Grupo de Pesquisa LEETRA "Linguagens em Tradução" (CNPq). 


\section{ABSTRACT}

This paper presents reflections on the interface between Translation Studies and New Literacy Studies through the lens of an applied proposal. The main objective resides in the discussion of the concept of rhythm and its pertinence to New Literacy Studies. I use the concepts of rhythm and scripture proper to Literary Studies as basis to enrich some questions of Applied Linguistics in order to envisage procedural aspects inherent in the transition between different modalities of language. I argue that academic writing disciplines should, also, take into consideration the practice of writing according to other discourse genres, including literary genre, in order to make students understand critically the necessary transitions/ translations in each case.

Keywords: rhythm; discourse genre; orality; process.

\section{Introdução}

Busco com este trabalho dar continuidade a reflexões que venho construindo na interface entre os Estudos do Letramento e os Estudos da Tradução.

Foi com o início de minha participação nas discussões do Grupo de Pesquisa "Letramento do Professor" (CNPq), há cerca de dez anos, que aprofundei e amadureci reflexões iniciais a respeito do que são as práticas de letramento, de um ponto de vista sócio histórico, assim como passei a rever certas postulações equivocadas, com as quais ainda convivia à época, particularmente aquela que coloca em posições dicotômicas a oralidade e a escrita, como se essas categorias remetessem a algo de fato encontrável na prática cotidiana da utilização da linguagem. Foi também ali, nos debates semanais, sempre em torno de leituras e reflexões teóricas, que comecei a esboçar a compreensão de que cada gênero do discurso em que nos engajamos requer de nós a simulação de um ethos, de uma identidade (Martins, 2010), algo que passei a compreender, posteriormente, conforme explicitarei aqui, como o processo de subjetivação inerente à linguagem.

De toda forma, como o olhar de todos os pesquisadores desse grupo estava preferencialmente voltado a questões que remetem aos processos de ensino e aprendizagem de línguas, uma inquietação ainda me acompanhou nestes últimos anos: se, por um lado, parece que hoje 
entendemos, de forma mais precisa e adequada, a variedade de textos nas modalidades oral e escrita, fato que já não nos permite falar genericamente em oralidade e escrita como realidades dicotômicas, por outro, carecemos, ainda, de uma explicação, também mais adequada e precisa, a respeito das formas de transição de uma para outra modalidade de linguagem, dentro daquela heterogeneidade de possibilidades a que nos remete o contínuo dos gêneros do discurso (Marcuschi, 2001), assim como suas possíveis hibridizações. Mais recentemente, graças a estágio de pesquisa no exterior (FAPESP 2015/24353-5), aprofundei reflexões em torno da obra do poeta, linguista e tradutor francês Henri Meschonnic e de sua fertilidade própria ao momento contemporâneo, do pensar sobre a inter e a transdisciplinaridade, e da pertinência da reflexão a respeito do texto poético para a abordagem dos textos em geral.

É a essa questão instigante - da forma de passagem de uma para outra modalidade de linguagem - que pretendo me dirigir, com base em aportes teóricos construídos na área da Semiótica da Cultura (Lotman, 1998; 2005) e dos Estudos da Tradução, de tal forma a poder pensar a respeito dos aspectos tradutórios do letramento, com ênfase particular para a reflexão em torno do componente pragmático no que este implica o ritmo e o processo de subjetivação que se constroem nos textos em geral, e no texto poético de forma particular.

\section{Algumas reflexões iniciais}

Em trabalho publicado há mais de dez anos (Martins, 2004), sugiro, de forma ainda rudimentar, dentro do ensejo de compreender a dinâmica processual própria à linguagem, a adoção do método inverso ou método dialético para se pensar a relação entre as modalidades oral e escrita. Baseio-me em Vigotski (1991:143), que recorreu, em um de seus trabalhos, "Psicologia da arte", ao "método inverso" com o objetivo de desvendar a essência da reação estética, buscando analisar formas desenvolvidas de arte, na certeza de que essa investigação revelaria "aspectos válidos também para formas menos desenvolvidas". Vale notar que essa explicitação, por parte de Vigotski, da existência de formas superiores e inferiores de arte - que pode não soar politicamente correta aos ouvidos pós-modernos - se coadunava com suas investigações acerca das relações entre os "conceitos cotidianos" e os "conceitos científicos" no desenvolvimento do pensamento infantil. 
Em momento posterior, quando participava das discussões no Grupo de Pesquisa "Letramento do Professor", desenvolvi melhor, a partir da categoria do ethos, a proposta de uma relação dialética que se poderia visualizar entre textos pertencentes a diferentes gêneros do discurso (Martins, 2007). Discuto de que maneira, tanto a criança, como o adulto se apropriam de diferentes formas de linguagem e, nesse mesmo processo, exercitam diferentes papéis sociais à medida que transitam de uma para outra modalidade de linguagem. Em linha semelhante de pensamento, em outros trabalhos, mostro insatisfação, do ponto de vista do processo de ensino e aprendizagem de línguas, com a pressuposição de um contínuo desprovido de transições, que iria do oral para o escrito (Marcuschi, 2001), e aponto para a necessidade de se vislumbrarem, em meio a esse percurso, os conflitos e confrontos de poder a ele inerentes. Posteriormente (Martins, 2010 e 2011), aponto para a etnicidade como fator de estilo (associando, nesse caso, ethos a estilo), sempre tendo em foco a transição de uma a outra modalidade de linguagem, e sempre pressupondo a passagem problemática por níveis hierárquicos, que necessitariam ser vislumbrados nos interstícios dessa transição.

Entendo, assim, que a abordagem que venho desenvolvendo distancia-se, em parte, daquela de Marcuschi (2001); diferencia-se, também, daquela de Rojo e Schneuwly (2006), que se constrói na linha da proposta do sistema de gêneros (Bazerman, 2005). Aqui também estamos, é claro, dentro de um sistema, cadeia ou circuito de gêneros, porém numa visada que não prevê apenas a conexão ou o aparentamento de um gênero com outro que lhe pareça próximo - como no caso, citado pelos autores, da conferência, dos slides em power-point em que esta se baseia, e de sua transcrição posterior; ou naquele, citado por Baltar et alii (2006), do conto de Allan Poe que, em aula de produção de textos, cumpre o papel de gerador de textos de outros gêneros, como o boletim de ocorrência, a nota de falecimento. Postula-se, na defesa que empreendo, que se leve em consideração, nos termos insistentemente propostos por Meschonnic (1982), o processo de subjetivação inerente à linguagem. Daí estarmos, de preferência, no âmbito da tradução, no que esta pode implicar a tomada em consideração da apropriação do aparelho formal da enunciação por parte de um Sujeito ativo e criativo, dentro de uma perspectiva sócio histórica (ou ético-política, conforme estaria mais de acordo com as postulações de Meschonnic), e não propriamente da retextualização, muito embora, em termos técnicos, 
ou seja, no que diz respeito ao trabalho pontual voltado às escolhas sintático-semânticas, possamos entender que, em alguns momentos, estas diferentes propostas mantenham pontos de confluência.

Vale notar que são duas as principais ressalvas que guardo com relação ao trabalho convencional voltado à reescrita tal qual vem sendo desenvolvido com base em Marcuschi (2001): a) a existência de certa idealização com relação ao que seja o "oral" e o "escrito", já que, apesar do assim chamado contínuo do oral para o escrito contemplar, conforme Marcuschi (2001:40), certa amplitude de textos pertencentes a diversos gêneros do discurso, dentro da pressuposição de uma variação que iria do mais informal (conversa cotidiana) para o mais formal (artigo científico), a prática corriqueira que se propõe centra-se em certa concepção mais restrita, em que o "oral" comportaria as marcas próprias de uma conversa informal, e a transposição para o "escrito" implicaria a formalização própria ao texto que tem características do texto acadêmico; b) a segunda ressalva, intimamente relacionada com a primeira, é aquela que me leva a ver nas atividades de retextualização e de reescrita como que uma versão renovada daquela prática antiga de correção de textos, com pouca margem para uma construção mais imaginativa por parte daquele que escreve, assim como para a motivação da prática voltada à construção genuína de um processo de subjetivação. Ou seja: na prática de reescrita e de retextualização, ainda aquele que escreve se vê excessivamente preso à versão original, às palavras do outro.

Pode-se dizer, assim, que, no processo de tradução, as palavras não podem simplesmente ser trocadas, substituídas, empreendimento que nos conduziria ao âmbito da paráfrase, do isolamento do signo (em relação ao processo discursivo), da Hermenêutica (enquanto procedimento de interpretação). As palavras necessitam ser traduzidas e, para isso, precisam, do outro lado, reencontrar um ritmo, uma corporalidade, que as transporte, carregando-as. É nesse sentido, aliás, que a tradução, em alguns casos, envolve ruptura e transcriação, particularmente na linha com que se vem compreendendo, nas últimas duas décadas, a tradução literária (Campos, 1992; Ottoni, 1998; Derrida, 2001)..

Lembro que, segundo Marcuschi (2001:37),

“(...) as diferenças entre fala e escrita se dão dentro do continuum tipológico das práticas sociais de produção textual e não na relação dicotômica 
de dois polos opostos. Em consequência, temos a ver com correlações em vários planos, surgindo daí um conjunto de variações e não uma simples variação linear".

Também Rojo e Schneuwly (2006:466), no entanto, guardam, nos seguintes termos, restrições semelhantes às minhas quanto a essa concepção:

"Embora a concepção brevemente exposta acima apresente uma versão bastante mais sofisticada das relações entre oral e escrito nos usos sociais da língua, esta ainda guarda um pendor tipológico e taxonomizante, e relações de semelhança e diferença - enquanto múltiplas variáveis - operam no interior do contínuo".

Lembro, por último, do desafio inerente à pesquisa na área de Linguística Aplicada, em que, por um lado, buscamos descrever como se dá, efetivamente, na prática cotidiana, o acesso aos diferentes gêneros do discurso nas modalidades oral e escrita; por outro, buscamos propor atividades de caráter pedagógico, portadoras de certo grau de simulação, que nos pareçam pertinentes para que se propicie esse acesso dentro do âmbito escolar.

Nesse sentido, parto, em princípio, do ensejo de aludir aos processos que se dão na transição entre diferentes práticas de linguagem; apresento algumas atividades de linguagem de teor didático-pedagógico desenvolvidas no âmbito acadêmico com vistas a propiciar maior visibilidade das questões teóricas às quais pretendo remeter; passo, por fim, por cogitações a respeito da tradução literária, a fim de explicitar melhor em que sentido a tradução pode propiciar a visibilidade a respeito da presença do ritmo nas organizações frasais.

\section{Aportes da semiótica da cultura: a semiosfera e a busca de um princípio heurístico}

De forma a ampliar a reflexão sobre o (s) letramento (s) a partir dos Estudos de Tradução, venho recorrendo à teorização do semioticista russo Yuri Lotman $(1998 ; 2005)$ a respeito da semiosfera, a qual, dentro de uma abordagem sócio histórica de teor marcadamente complexo, implicaria o espaço semiótico necessário a toda e qualquer semiose. 
Segundo o autor, o conjunto de formações semióticas precede funcionalmente cada língua singular e isolada, sendo uma condição de sua existência. Nesse sentido, somente dentro desse espaço os processos comunicativos se tornariam possíveis. A divisão entre centro e periferia é, por sua vez, uma lei da organização interna da semiosfera: há um limite, uma fronteira entre a semiosfera e o espaço não semiótico ou extrassemiótico. A fronteira semiótica é representada pela soma de filtros bilíngues: ao passar por eles, o texto é traduzido, fato que não implicaria, necessariamente, a tradução de uma língua em outra língua que seria considerada estrangeira. A tradução se dá, de fato, a todo instante, como mecanismo intrínseco ao funcionamento de toda e qualquer linguagem humana (Martins, 2014).

Entende-se que a semiosfera compreenda, assim, um grupo de semiosferas interligadas, sendo que cada uma delas participa do diálogo e envolve um espaço de diálogo. Segundo Yuri Lotman (2005:206, tradução minha),

“(...) na realidade, sistemas distintos e funcionalmente monossemânticos não existem de forma isolada. Sua articulação é condicionada por necessidade heurística. Nenhum deles é, de fato, efetivo se tomado isoladamente. Eles só funcionam quando imersos num contínuo semiótico específico preenchido de modelos semióticos multivariantes situados numa gama de níveis hierárquicos".

É fato que, há mais de quarenta anos, também a partir de uma visada sócio histórica, o psicólogo russo Leontiev (1975), pertencente à Escola de Vigotski, já questionava certo modelo teórico que ainda ressoa em trabalhos contemporâneos, em função da comprovação de que, na percepção da linguagem, o ser humano não age, simplesmente, como se ele próprio fosse um sistema de filtragem, mas, em vez disso, cria e seleciona estratégias ou métodos de procedimento, de modo que, em certas situações, os processos de percepção da linguagem não são algorítmicos - isto é, estritamente determinados pelas situações específicas - mas, de preferência, governados por um "princípio heurístico". Ou seja, em vez de imaginarmos que sempre, quando falamos, selecionamos in loco determinadas estratégias de acordo com a identificação da situação de uso, passamos a compreender que a seleção muitas vezes precede e determina a análise, ou, mesmo, pode ser feita com base em um conjunto incompleto de sinais. 
Desponta, assim, o fato de que, no processo de aquisição de linguagem, o que se desenvolve não é a linguagem em seu sentido mais usual, nem o método de atualização de mecanismos internos; o que vai se transformando é a natureza da interação que se dá dentro do sistema de recursos linguísticos de que dispomos. Nesse sentido, vale chamar a atenção para aquelas pesquisas que hoje vêm sendo desenvolvidas no campo das neurociências e da cibernética de segunda ordem, e que confirmam o pressuposto de Leontiev da necessidade da postulação de um princípio heurístico, assim como de sua caracterização antecipatória e recursiva. Vejam-se nesse âmbito os trabalhos de Anokhin, Luhman, Varela e Maturana, Heinz Von Foester, que apontam para processos dinâmicos, recursivos, iterativos, em que todos os seres vivos estão envolvidos, e que implicam a participação ativa e intencional de cada indivíduo, porém não apenas do ponto de vista consciente e racional, mas em amálgama complexo que pressupõe a inter-relação dinâmica entre mente e corpo, intelecto e emoções.

Em todos os casos, postula-se que os seres vivos são motivados por afetos, dando-se uma oscilação contínua entre corpo e mente que seria a base para a construção do sistema comum de noções. A base da sociabilidade residiria na ressonância como princípio gerador da reciprocidade, passando a ser previstos, assim, dois patamares intimamente interligados: aquele do sentido ("sense"), que diria respeito à ressonância e à coordenação das emoções; e aquele do significado ("meaning"), que diria respeito à organização da reciprocidade. Em meu entender, no entanto, quando na área dos estudos linguísticos nos referimos ao diálogo e aos fatores intersubjetivos, estamos, muito frequentemente, levando em consideração apenas este segundo patamar, fato que provavelmente é o responsável pela conotação algorítmica em que muitas vezes acabamos por recair.

Vale notar, ainda, que, em seu artigo seminal, Yuri Lotman (2005) insiste no princípio de diferenciação ao citar o enantiomorfismo - presença de formas simétricas que não podem se sobrepor, como no caso do reflexo no espelho - como a forma mais comum da combinação entre identidade e diferença que é a base para a existência do diálogo e da geração de significado: as duas partes do espelho são iguais e desiguais (no que se refere às posições de direita e esquerda). É nessa medida que, por um lado, os sistemas são heterogêneos e não idênticos; 
por outro, são facilmente convertidos, o que assegura a tradutibilidade mútua. $\mathrm{O}$ enantiomorfismo representa o mecanismo primário do diálogo porque, para que este possa se dar, os participantes precisam ser diferentes e, simultaneamente, conter em sua estrutura uma imagem semiótica de contraparte, fato que evidencia o papel necessariamente ativo e criativo dos sujeitos envolvidos.

Talvez não se trate de algo muito diferente daquilo a que Goffman (1996) pretendeu aludir quando falou dos palcos que frequentamos e dos papéis que ali representamos. Resta-nos, no entanto, assim me parece, no âmbito dos estudos linguísticos, a descrição mais apurada da forma com que esses papéis se enredam, se entranham no funcionamento sintático-semântico-pragmático dos enunciados que proferimos, e nos aspectos rítmicos que se fazem presentes. Na linha, acredito, do que Meschonnic (1970:15-16) nos aponta - "O ritmo é gramatical (...). $O$ ritmo é às vezes a única gramática, o único sentido do texto (...). Os acentos e sua sintaxe inscrevem no texto uma diç̧ão. Eles lhe atribuem sua qualidade oral (...)" - entendendo-se, como anunciarei adiante, o sentido diferenciado que o linguista francês atribui a "oralidade".

Em síntese, conforme já anunciei no item anterior, trata-se de uma forma de descrever os fenômenos linguísticos dentro de uma complexidade sócio histórica da qual o contínuo convencional dos gêneros do discurso nos oferece, apenas, um recorte simplificador. Estamos diante de diferentes esferas semiológicas de atividade humana, dotadas de fronteiras e limites para cuja transposição a tradução se faz necessária. Essas esferas são, por sua vez, portadoras de ressonâncias próprias, de caráter antropológico e sócio histórico. É nesse sentido, por exemplo, que quando em disciplinas universitárias nos centramos na prática da escrita acadêmica, sem contextualizá-la de forma crítica e problemática, nem relacioná-la com outras escritas, o trabalho que fazemos resulta necessariamente idealizado e caricatural, além de despersonalizado. De toda forma, a proposta que trago aqui, embora se relacione com o Modelo dos Letramentos Acadêmicos proposto por Lea\&Street (2006), em função de seu viés crítico, transcende-o, por conta da inclusão do texto de caráter poético, sem o qual, em meu entender, nenhuma proposta será genuinamente crítica. 


\section{O ritmo e os processos de tradução}

Octávio Paz (2006), em "Tradução: Literatura e Literariedade", afirma: "Aprender a falar é aprender a traduzir: quando a criança pergunta a sua mãe o significado desta ou daquela palavra, o que ela realmente quer é que traduza para sua linguagem o termo desconhecido". Até aí, é claro, a questão pode sugerir certa banalidade, uma vez que estamos lidando com palavras isoladas, como se a criança perguntasse à mãe "O que é contador?" e ela lhe respondesse: "É $O$ homem que ajuda a mamãe a fazer as contas", dentro de um enunciado que trabalha a tradução de forma expansiva, ou metonímica, se quisermos apelar para a diferenciação estabelecida por Jakobson (1969) entre os dois procedimentos fundamentais da tradução, a metonímia e a metáfora.

A questão se torna, no entanto, mais complexa e desprovida da aparente banalidade, quando nos lembramos do alerta de Henri Meschonnic (1982:13) - a respeito do papel que o ritmo deveria ter nos estudos da linguagem, como "uma parte que é talvez a mais importante", e da necessidade de se construir uma teoria geral sobre o ritmo, de forma a retirá-lo dos espaços mais restritos do texto literário ou da língua falada. Fundado na crítica à forma superficial e limitada com que o ritmo é abordado apenas do ponto de vista da métrica, e baseando-se particularmente em Benveniste (1976a), Meschonnic (1982:225 e 363) propõe-se a ver o ritmo como "(...) também a estruturação em sistema do que ainda não é sistema" e "estruturação de conjunto”. É, por sua vez, remetendo a Meschonnic, que Jurado Filho (1996:28) propõe “(...) entendermos o ritmo como um recurso organizador da linguagem. É por meio do ritmo que podemos, pois, pensar numa integralização de pontos de vista na enunciação, numa organização multidimensional da linguagem".

O ritmo seria portador dos aspectos antitéticos da continuidade e da descontinuidade da linguagem, algo a que Jurado Filho remete, com base em Benveniste (1976a), como fazendo parte do jogo entre aspectos paradigmáticos e sintagmáticos da linguagem, um jogo que se daria entre o sistema linguístico virtual e as configurações linguísticas específicas. Mais adiante, nessa linha de raciocínio, Jurado Filho (1996:32) chega a esta definição: “(...) o ritmo é a organização 
singular dos elementos de qualquer atividade linguística, oral ou escrita", que se manifesta "como a disposição de elementos descontínuos, fragmentários, num contínuo, num fluxo". Creio, neste caso, que não estamos longe da concepção de ritmo em Bakhtin (1997); é fato, no entanto, que as reflexões advindas de Meschonnic contribuem, de preferência, para um enfoque de aspectos microtextuais (o léxico, a sintaxe, a prosódia), enquanto que, com Bakhtin, somos levados a refletir com mais cuidado sobre o acento apreciativo (ideológico) que o ritmo comportaria. Vejamos a definição de Meschonnic (1982:216217, tradução minha):

"Defino o ritmo na linguagem como a organização das marcas pelas quais os significantes, linguísticos e extralinguísticos, (sobretudo no caso da comunicação oral) produzem uma semântica específica, distinta do sentido lexical, e que chamo de significação: isto é, os valores próprios a um discurso e apenas a ele. Essas marcas podem se situar em todos os níveis da linguagem: de tonicidade, de prosódia, léxico ou sintático. Constituem, juntas, uma paradigmática e uma sintagmática que neutralizam precisamente a noção de nível. Contra a redução comum do sentido ao léxico, a significação pertence a todo o discurso, está em cada consoante, em cada vogal que, como paradigma e como sintagma, desencadeia séries"

Em texto curto e de caráter de manifesto, Pajevic (2014, tradução minha) nos alerta para o processo discursivo presente na linguagem, fazendo-nos lembrar da diferença estabelecida por Benveniste entre os aspectos semiótico e semântico inerentes a ela:

“Como signo, a língua não é considerada um processo criativo: o signo comunica conhecimento, ou seja, conhecimento já existente. Nesta concepção, a língua serve apenas como uma ferramenta em relação às coisas do mundo exterior. Considerada como língua [e não como signo], no entanto, a língua torna-se um processo vivo, renovando-se continuamente, criando o significado que não existe independentemente deste processo. Não são as palavras que constituem o discurso mas, ao contrário, as palavras emergem do discurso, como Humboldt sinalizou - só no contínuo elas fazem sentido. O que acontece com a língua enquanto língua é, assim, na linha de Benveniste, não uma semiótica onde os signos são reconhecidos, mas uma semântica em que o discurso é compreendido".

No próximo item apresento exemplos de atividades realizadas com fins pedagógicos no ambiente acadêmico, destacando o fato da 
simulação que se faz presente, nesses casos, de forma relativamente consciente e intencional, ou seja: diante da tarefa da produção de texto em dada atividade de linguagem, o graduando se investe de determinado ethos/pessoalidade atribuindo, de forma proposital, dado ritmo a seu texto, dentro da compreensão implícita desse tipo de funcionamento que, passando pelas escolhas lexicais propriamente ditas, transcende-as e atinge a organização sintática/sintagmática, na medida da assimilação de dado ritmo às estruturas frasais de acordo com o gênero do discurso ao qual o texto se alinharia. Sem dúvida, dentro de uma compreensão prototípica do que seria próprio, em termos léxicos, sintáticos e rítmicos, aos textos pertencentes a dado gênero do discurso. Na medida da apresentação dos dados, voltarei à discussão de alguns elementos teóricos, dentro do ensejo da união entre teoria e prática, assim como da compreensão da necessidade da prática da escrita e da tradução para uma melhor compreensão dos aspectos teóricos que envolvem a (s) linguagem (ns).

\section{Alguns exemplos para análise}

Em oficina de escrita criativa desenvolvida com a participação de graduandos e pós-graduandos de nosso Departamento de Letras no primeiro semestre letivo de 2011, propus que cada um dos participantes lesse um texto diferente, sendo um deles a crônica "Piscina", de Fernando Sabino. ${ }^{3}$ Após a leitura, propus que cada um dos participantes elaborasse um texto diferente, escrito de acordo com outro gênero do discurso, mas que, à sua maneira, se apresentasse como tradução do texto original. Não houve interferência da minha parte no decorrer da produção de texto propriamente dita. É digno de nota, porém, o fato de que, na introdução à oficina, eu me referi à forma com que a linguagem humana sempre abriga processos tradutórios, algo particularmente reconhecível na transição que se dá na escrita de textos pertencentes

3. Disponível em http://paredeimaginaria.blogspot.com.br/2009/08/piscina-de-fernandosabino.html (Acesso em 29/07/2016). Trecho da crônica original: "Era um ser encardido, cujos molambos em forma de saia não bastavam para defini-la como mulher. Segurava uma lata na mão, e estava parada, à espreita, silenciosa como um bicho. Por um instante as duas se olharam, separadas pela piscina. De súbito, pareceu à dona da casa que a estranha criatura se esgueirava, portão adentro, sem tirar dela os olhos. Ergueu-se um 
a gêneros do discurso diferenciados, de acordo com as esferas de atividade em que são produzidos.

Apresentarei, em seguida, alguns dos textos que resultaram do diálogo com a crônica de Sabino, comentando, brevemente, a respeito de como se constrói o estilo e o processo de subjetivação (Meschonnic, 1982) em cada caso. Chamo a atenção, de toda forma, para o fato de que se trata, neste caso, de um trabalho bastante rudimentar, porém que, em meu entender, aponta para possibilidades férteis de trabalho pedagógico voltado à produção de textos orais e escritos, e para a compreensão, ao menos inicial, da oralidade a que remete Meschonnic (1970), e do ritmo que lhe é inerente. Destaco, de toda forma, que o linguista francês (Meschonnic, 2008) estabelece diferença entre ritmo e estilo, como também aponta para a diferença entre o ritmo e a oralidade mais específicos do texto poético, em contraste com os ritmos retóricos e culturais, regidos por leis do discurso, que acredito serem mais adequados para se pensar nos exemplos de que tratarei, particularmente no caso da sinopse.

Remeto, entretanto, à ponderação de Bakhtin (1992), segundo quem o estilo envolve não uma forma e, sim, um comentário, na medida em que sempre estarão presentes, no mínimo, dois sujeitos, assimetricamente dispostos na "arena de combate" em que se dão os processos da significação. Se é fato que o estilo se constrói na medida de um comentário que se tece com relação a outros textos, sejam os prototípicos do gênero em pauta, sejam aqueles com os quais dialoga irônica e problematicamente, também é fato, de toda maneira, que são as marcas textuais das escolhas sintático-semântico-pragmáticas pontuais (entendendo-se, na linha do pensamento de Meschonnic, o ritmo como elemento articulador/organizador dessas escolhas) que me autorizam a reconhecer a existência desse processo.

Vale, ainda, retomar, aqui, até para compreendê-la melhor, a postulação de Lotman (2005), mencionada acima, segundo a qual não existem sistemas monossemânticos isolados, já que nada que se tome isoladamente pode, de fato, ser efetivo ou significativo. É assim que, por exemplo, outros tantos textos reverberam, já desde seu título, em "Era uma casa de gente rica" (Texto 2), e é a partir dessa proliferação de sentidos que, de fato, esse texto adquire a força de seu sentido próprio, de sua significação. 

forma implícita, com certa tradição da produção literária em versos. Ao escolher a estrutura composicional do poema, parece entender que este deva, de preferência, ser rimado, fato que chega a levá-lo - na passagem "definir quem adentrava não conseguiram" - a trabalhar na linha das inversões próprias ao hipérbato, mesmo que, exatamente nesse ponto, não haja resultado a rima.

\section{Texto 1}

\section{Lado a lado}

Lugar idealizado: beleza, conforto, esplendor Convívio lado a lado: barraco, tristeza e horror.

Certo dia, nitidamente, uma realidade com a outra se chocou.

Uma visita indesejada a linda casa recebeu

E quem nela se esbaldava, ao redor de uma bela piscina, estremeceu

Os donos da esplendorosa casa definir quem adentrava não conseguiram

Criatura esfarrapada que como uma raio a invadia

Passos lentos e cautelosos à piscina dirigiu-se, lentamente agachou-se

E a lata que trazia, enchia e não esquivou-se

Mais estranho foi depois: sem olhar, nem nada dizer

Tal criatura se foi.

Toda a cena foi tão rápida que só depois fez sentir

A tensão do momento e, é claro, fez refletir:

Os dois mundos e a distância eram maiores do que parecia.

À sua maneira, o escrevente apropria-se (no sentido presente em Benveniste, 1976b, do processo de apropriação do aparelho formal da enunciação) da linguagem, e a subjetiva, construindo a oralidade como modo de enunciação poética, intimamente associada ao ritmo. Este, por sua vez, constrói-se de forma global, pan-rítmica, através do trabalho conjunto da versificação, da rima (interna ao verso, assim como no seu final), da pontuação, da assonância, da aliteração.

\section{Texto 2}

Era uma casa de gente rica

Era uma casa

de gente rica, 


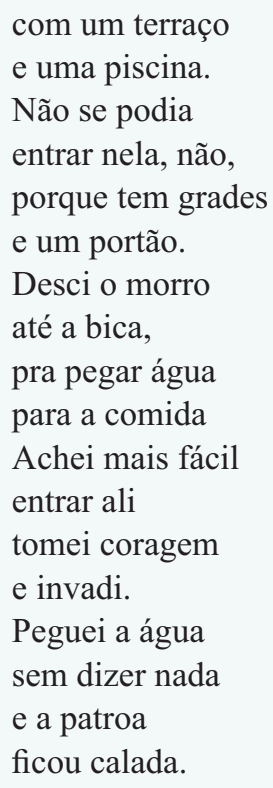

Segundo a autora deste texto, ele seria uma paródia de "A casa", cantiga de Vinicius de Moraes. Comento agora, de forma rápida, a respeito de algumas das opções sintático-semânticas que se podem detectar no contraste deste texto com a crônica em que se baseou. Sem dúvida, um ponto fundamental presente nesta segunda proposta de tradução é a existência da tomada da palavra - como parte do processo de subjetivação da linguagem - por parte do "ser encardido", do "bicho", daquele personagem que, no texto de Sabino, não tem voz, não participa da enunciação, sendo, assim, em vários sentidos que se entrecruzam, uma não-pessoa. Na tradução/transcriação/transposição, é esta personagem, no entanto, quem fala, quem relata seus feitos, seus atos heroicos: "Tomei coragem/e invadi". Outro aspecto de destaque reside na forma com que dialoga ironicamente com a música de Vinícius de Moraes, gerando o contraste implícito com a letra da música infantil ("Era uma casa/tão engraçada/não tinha muro/não tinha nada"), certamente embutida na memória de infância da maioria de nós, leitores. Na infância ingênua, a casa sem muros, sem nada; na arena do combate adulto, a grade, o portão, a invasão. A vida deixou de ser tão engraçada. E, no que tange nossa ênfase neste trabalho, vale destacar a presença do ritmo, das rimas e assonâncias que contribuem para a criação de uma pan-rítmica organizadora do dizer. 
Com base na mesma crônica, um terceiro participante produziu outro texto. ${ }^{4}$

\section{Texto 3}

\section{$\mathrm{O}$ homem rico e o telefone}

Certo dia o ricaço resolveu tomar banho de sol em sua magnífica residência. Com uma pompa enorme e um drinque em uma das mãos aproveitava o dia ensolarado. Sua mulher, acostumada com a vida mansa, dormia profundamente, parecendo não se importar com o mundo que existe aqui fora.

Então aparece uma mulher com uma lata na mão, maltrapilha e aparentando debilidade física. Ela se aproxima lentamente, se esgueira pelo portão entreaberto, mergulha a lata na piscina e afasta-se com a lata cheia.

$\mathrm{O}$ homem olha a cena calmamente e se lembra que a vizinhança em que mora está situada perto de uma favela em formação. Prontamente retorna para sua casa, pega o telefone, contata o delegado do seu distrito. Em pouco tempo as pessoas desaparecem e um shopping é erigido no local dos barracos.

Moral: Poder, dinheiro e um telefone resolvem qualquer problema.

Neste caso, é particularmente pela presença da moral ao final do texto, como característica pertencente à estrutura composicional de uma fábula, que percebemos a transição de um para outro gênero; caso contrário, talvez nos sentíssemos ainda diante de uma crônica, e apenas no âmbito da paráfrase e da retextualização. Aqui, chama-me a atenção certa opção lexical que, à sua maneira, configura-se como comentário a respeito da escolha que se dera no texto de Sabino, como também envolve certo comentário cotextual, como parte da própria opção pelo gênero "fábula" e por seu caráter moralizante. Sequências como "o ricaço", "sua magnifica residência", "com uma pompa enorme", "acostumada com a vida mansa", "dormia profundamente", "não se importar com o mundo que existe aqui fora", "é erigido" redesenham aspectos presentes na crônica, que tratam de traduzir. É nesse redesenho que se faz a tradução, a transcriação, a transfiguração, a transcendência, para além da retextualização ou da reescrita. Note-se, ainda,

4. Lembro que cada um dos participantes produziu seu texto sem ter conhecimento das demais produções, sendo que só ao final da oficina houve a socialização das mesmas. Lembro, ainda, que obtive a autorização dos participantes da oficina para a publicação de seus textos. 
como na estruturação frasal da moral - "Poder, dinheiro e um telefone resolvem qualquer problema" - ecoam as "Fábulas Fabulosas" de Millôr Fernandes. Também é digna de nota a forma com que o ritmo se constrói nos dois períodos iniciais do último parágrafo: no primeiro, o ritmo organizador se estrutura através de um período longo, sem uso de vírgulas e carregado de nasalizações; em contraste com o segundo, recortado por vírgulas e atravessado de consoantes oclusivas.

Lembro, diante do fechamento que o autor, neste caso, atribui a seu texto, a ponderação de Bakhtin (1992) com relação ao "dixit" que caracteriza cada enunciado e que lhe fornece o acabamento necessário para que se proporcione a abertura ao diálogo e a expectativa de uma resposta por parte do coenunciador. Das três traduções/transcriações, é nesta última que o "dixit" se dá de forma mais explícita e acabada. Não porque o autor, neste caso, tenha nos contemplado com uma solução inédita; ao contrário: ele se apropria de uma solução antiga, de uma forma (fôrma) já existente, e a carnavaliza. É certo que a carnavalização já não surte o mesmo efeito que aquela produzida por Millôr, mesmo porque se faz na esteira de Millôr. Porém, de toda maneira - em função do diálogo que seu texto trava com a crônica a que responde, traduzindo-a - resulta fortemente o efeito de sentido do "dixit", que, em meu entender, é um dos pontos chave da construção da organização rítmica.

Nos exemplos que venho explorando, vemos a passagem ou transposição do texto pertencente a determinado gênero para outro, de forma diferente, conforme já sinalizei, daquela prevista no trabalho com o circuito de gêneros, já que nos colocamos, a propósito, no terreno da experimentação com a linguagem, com a ênfase particular para a produção de texto de viés literário. Se é fato que, no caso do circuito de gêneros, tal qual entrevisto por Baltar (2006), pode ser dada margem à emergência mais marcada do processo de subjetivação, também nos parece claro que, explicitando-se a caracterização da oficina de escrita criativa e dando-se oportunidade à escolha aleatória do texto a ser produzido, motivamos de forma mais decidida a tendência à busca pela escritura, em sua conotação literária.

Vale notar, entretanto, que pensamos sempre em termos de gradientes tensionais, de modo que, seja como for, de forma mais ou menos 
visível, o ritmo estará sempre presente enquanto elemento articulador do contínuo textual, apenas talvez mais apreensível no texto que reconhecemos como pertencente ao gênero literário.

Passo agora, a propósito, mesmo porque neste caso estaremos mais próximos da proposta de circuito de gêneros, à menção de dois textos do gênero "sinopse", produzidos por graduandos do curso de Licenciatura em Letras em outro contexto, no ano de 2013, em duas ofertas diferentes do curso na modalidade a distância "Tópicos em Língua Portuguesa: Linguagem e discurso". Nestes casos, os participantes dos cursos foram motivados a escolher qualquer filme de sua preferência e escrever uma sinopse a seu respeito. Não houve nenhuma explicação prévia de como se devem escrever sinopses. Reproduzo apenas alguns trechos de duas dessas produções, com o intuito de comentar a respeito da construção do ritmo que se faz presente neles de forma mais visível.

\section{Texto 4}

\section{Somos tão jovens}

O filme conta a trajetória do cantor e compositor brasileiro Renato Manfredine Júnior (vivido pelo protagonista Thiago Mendonça), que se tornou conhecido como Renato Russo, em homenagem feita aos filósofos Jean Jacques Rousseau e Bertrand Russel.

(...)

Canções como "Eduardo e Mônica”, "Geração Coca-Cola”, "Ainda é cedo", "Que país é este", "Será” e "Faroeste Caboclo” podem ser apreciadas nesta obra biográfica e revividas por todos que fizeram parte desta geração marcada por sonhos e ideais.

Um filme emocionante, apaixonante e inspirador!

\section{Texto 5}

\section{O Grande Gatsby}

Arrasando desde a bilheteria até o Festival de Cannes 2013, onde foi convidado para abrir o evento, "O Grande Gatsby" vem arrancando suspiros por onde passa e lotando cinemas, nada mais justo após um atraso na estreia.

Baz Luhrmann conseguiu se afirmar como um diretor queridinho da crítica, dirigindo músicas e filmes épicos, onde ele dá toques épicos que é quase como uma assinatura. Juntamente com a Warner Broz, Baz fez com que o filme superasse todas as expectativas e fosse considerado uma obra de arte pela crítica. 


\section{(...)}

Em meio a imensos conflitos, luxuosas festas, traições e romance proibido "O Grande Gatsby" passa de geração em geração, deixando rastros de sua imortalidade. Um filme memorável e apaixonante.

No trabalho com graduandos em Letras e na observação de suas produções, chamou-me, de forma mais marcada, a atenção o ritmo diferenciado que as sinopses comportam, se comparadas com textos pertencentes ao gênero acadêmico, seja a resenha, por exemplo. Também ficou claro, ao trabalhar com esse gênero junto aos jovens, o quanto certo protótipo do gênero sinopse lhes é familiar e fornece o parâmetro para a construção de seus textos. Seria desnecessário, de resto, lembrar que já não faz sentido falarmos nas tão mencionadas "marcas de oralidade na escrita", pois certamente não é disso que se trata, e por vários motivos: seja pela observação, que já fiz logo no início, de como é equivocada a dicotomia oralidade/escrita; seja porque o que temos não são, de fato, marcas de oralidade, mas opções sintático-semânticas prototípicas (entendendo-se o protótipo como sociohistoricamente construído) que se organizam dentro de certo ritmo ou cadência, própria de textos pertencentes a cada gênero, e mais reconhecíveis no gênero literário. Nessa linha de raciocínio, a oralidade e sua marcas não fazem parte de algo indesejável, ao contrário. Há oralidade, tanto na modalidade oral, quanto na escrita, e o que ela sinaliza é a presença do Sujeito na linguagem, ou seja, o processo de subjetivação.

Vale anotar, aqui, que Meschonnic (Ancet, 1997, tradução minha), ao propor a tripartição entre o falado ("parlé"), o escrito ("écrit") e o oral ("oral"), refere-se à oralidade nestes termos:

“(...) só a escritura, como subjetividade máxima da linguagem, realiza plenamente a oralidade. Mesmo porque a oralidade não é, para mim, essa confusão com a fala, mas este modo de significação da linguagem em que o ritmo e a prosódia dominam, conduzem a dança. Na escrita e no falado. De fato, é essencialmente na escritura, no sentido literário da palavra, que se constata isso".

Meschonnic (1982) define o ritmo como a organização da "parole" na "écriture", chamando a atenção para a escuta da pan-rítmica própria à oralidade, ou seja, à presença do corpo na voz, e para a necessidade 
de se analisar o processo e a força do dizer, e não só o significado. Ritmo como organização do movente ("mouvant"), do contínuo, a organização do movimento da palavra na escritura, a organização de um discurso por um Sujeito, e de um sujeito por seu discurso (Meschonnic, 1995); ritmo que engloba a prosódia e a entonação (no caso da fala); ritmo como operador do sujeito e do discurso, visto, nesse caso, em estado performativo, e retomando-se, com isso, a serialidade do texto (Meschonnic, 1982).

É, assim, dentro da convicção de que não há, na realidade, textos que se produzam ou consumam de forma isolada, que vimos trabalhando, em disciplinas de produção de textos no curso de Licenciatura em Letras, com a variedade de textos que transcende aqueles do âmbito estritamente acadêmico (resenhas, artigos, monografias). Nesse sentido, torna-se fértil a vivência com o gênero sinopse e com sua especificidade rítmica para que se apreenda, contrastivamente, a especificidade da cadência presente na resenha acadêmica, com a qual a sinopse mantém certo aparentamento, de preferência, pela percepção das diferenças que comportam em vista das diferentes semiosferas em que circulam, cada uma provida de seu ethos próprio, e de suas ressonâncias rítmicas.

Notemos, de resto, nos textos (4) e (5), como é particularmente no fechamento do texto, enquanto "dixit", que se dá a ocorrência de certa fórmula rítmica, própria das sinopses. Também a presença do gerúndio e da voz passiva, em conjunto com expressões como "obra biográfica", "atraso na estreia", "queridinho da crítica", "toques épicos", "como uma assinatura", "de geração em geração" contribuem para a criação da pan-rítimica marcada, também, pela alternância entre períodos longos e curtos. É através da rítmica que reconhecemos a presença da persona adequada ao processo de subjetivação típico (ou prototípico) da sinopse.

\section{Conclusão}

Os textos que analisamos, tendo sido produzidos dentro de processo intencional de ensino e aprendizagem de línguas, indiciam a presença de aspectos tradutórios nas práticas de letramento, os quais implicam, conforme sinalizei de início, a presença de diferentes se- 
miosferas providas de ethé socialmente construídos em que sentido e significado se imbricam em amálgama atravessado de cadências rítmicas. Não seria excessivo lembrar que, se as cadências, ritmos e ressonâncias se impregnam nos textos, sejam orais ou escritos, isso se dá pela continuidade com que aspectos presentes na realidade sócio histórica e nos seus sujeitos deixam suas marcas nos produtos semióticos que aí circulam.

A criação de textos a partir de outros textos, na primeira oficina que mencionei, transpondo-os para as esferas de outros gêneros discursivos, certamente deixa mais clara a presença da poiesis, da escritura, seja porque os autores, nesses casos, escolheram a propósito compor textos da esfera literária (poema, fábula), mesmo não tendo sido orientados nessa direção (mas talvez em função do fato de o texto "Piscina" ser, ele próprio, de caráter literário). Já no caso da escrita da sinopse, pode-se dizer que em parte foge do gênero literário, em parte não, se considerarmos os aspectos de continuidade e hibridização entre gêneros; nesse sentido, a sinopse estaria mais próxima do texto literário, em função dos aspectos léxico-sintáticos, e também rítmicos, com que trabalha, do que a resenha de caráter acadêmico. Daí defendermos a necessidade do trabalho com oficinas de escrita criativa nos diversos cursos, não só nos de Letras, de tal forma, em parte, a propiciar o trabalho humanístico e cidadão com a linguagem em sua força criativa, em parte a propiciar para que o graduando visualize melhor aquilo que está sendo apagado na construção dos textos da esfera acadêmica, e, de resto, possa se questionar a respeito dessa necessidade. Possa, ainda, se dar conta de como a oralidade se relaciona com um grau mais intenso de subjetividade e de corporalidade na linguagem (seja ela falada ou escrita), da erotização da linguagem, algo que é apagado nas exigências ritualísticas do texto de teor acadêmico.

Retomo, para finalizar, palavras de Meschonnic (2010:19-21, tradução minha), lembrando que as considerações do linguista francês com relação à tradução interlinguística são também, em meu entender, aplicáveis à tradução intralinguística, ou seja, aos processos de reescritura na mesma língua, para os quais venho chamando a atenção aqui:

“Chamo então as traduções de apagantes, já que elas apagam o ritmo e o significante (...) O problema poético é dessemiotizar para fazer entender uma semântica sufocada pela semiótica, uma semântica serial. (...) O significante, 
na sua semântica serial é a força. Traduzir-escrever é traduzir a força. (...) mas a força é o que leva e traz o sentido. É o movimento do sentido. Nada mais simples. A coerência do continuum, contra a coerência do signo (...) É toda a diferença entre atividade e produto".

\section{E conclui:}

"Está claro, então, que escrever supõe repensar toda a teoria da linguagem. E que traduzir é a prática que, mais do que qualquer outra, coloca-a em jogo. A conclusão é que o desafio do traduzir é transformar toda teoria da linguagem. Sim, uma verdadeira revolução cultural".

O poeta, linguista e tradutor refere-se, aqui, à fertilidade da tradução literária. Da minha parte, trago suas cogitações para pensar sobre os processos tradutórios que se dão continuamente, na composição e estruturação de qualquer texto, dentro da convicção, junto com Otávio Paz, de que a tradução está no âmago de toda linguagem. E da convicção, simultânea a esta, de que, se há tradução, há corpo e há ritmo na linguagem.

Os exemplos que explorei apontam, de forma ainda tímida, para as possibilidades férteis do trabalho nessa direção; ainda tímida, pois, ao traduzir, cada um dos autores - às vezes mais, às vezes menos - esteve preso a esquemas prototípicos que, implicitamente, julga ser necessário cumprir. Vale lembrar, de resto, que, seja como for, as composições se deram dentro do espaço acadêmico, fato que pode explicar as eventuais limitações.

Nesse sentido, outra possibilidade fértil, na linha das oficinas de Escrita Criativa, e que contribui para aguçar as percepções do leitor com relação aos recursos linguísticos e rítmicos presentes em dado texto, é aquela da dimensão proposta por Clive Scott (2012:187, tradução minha):

“(...) motivar o leitor do texto de origem ('source text') a escrever suas respostas, seus insights e associações particulares, em criações rápidas de um texto de chegada ('target text'), de modo que o texto de chegada possa ser visto como o texto de origem re-textualizado, tendo recebido novas coordenadas expressivas, no aqui e agora do ato de leitura". 
Fecho este artigo, a propósito, com proposta que efetuo de leitura/ tradução de trecho do poema "A pantera", do poeta alemão Rilke ${ }^{5}$, em que transporto alguns de seus versos para a dimensão da produção artística, ao levar em consideração a forma com que os aspectos rítmicos presentes no texto original me afetam como leitora.

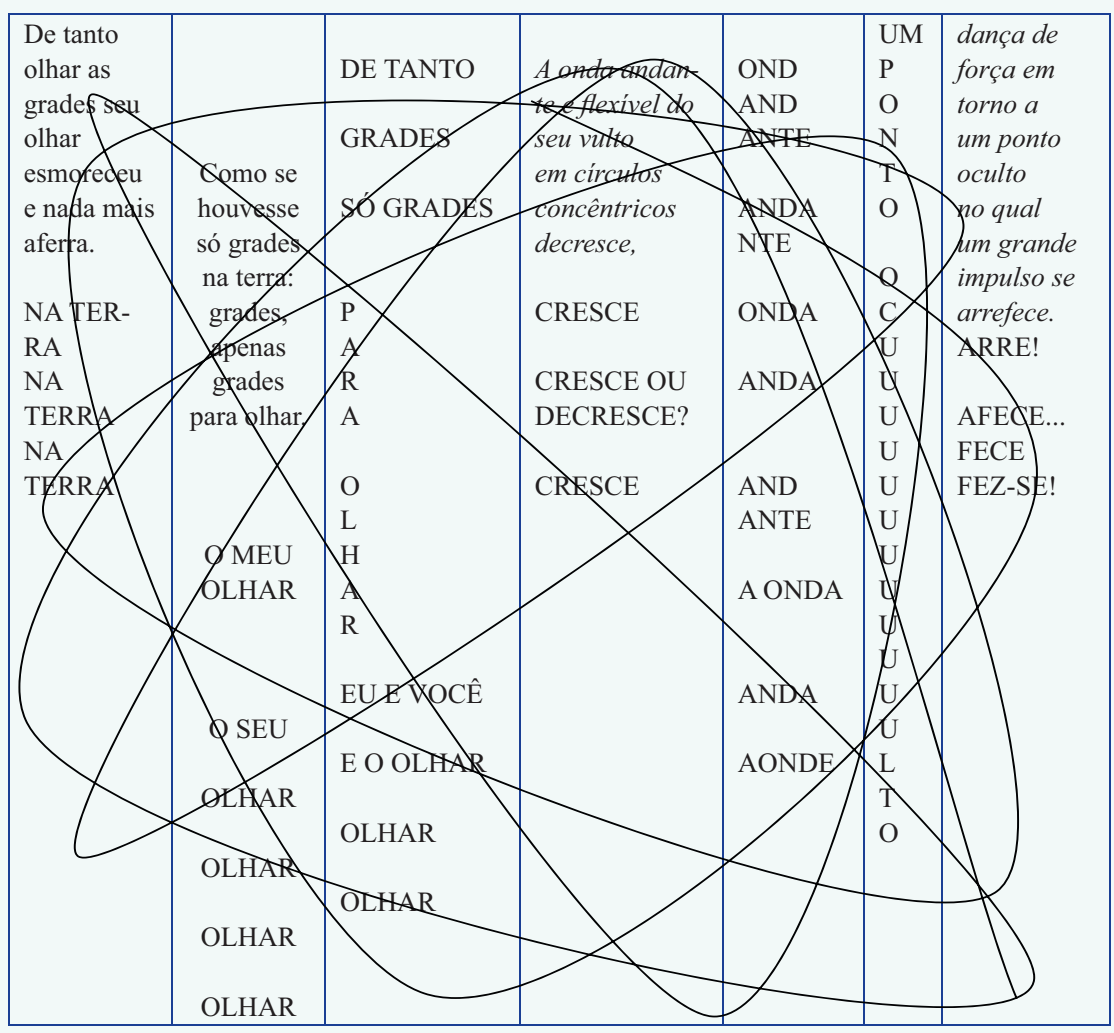

Recebido em: 29/07/2016

Aprovado em: 22/02/2018

E-mail:msilviam@ufscar.br

5. Estrofes de "A Pantera”, de Rainer Maria Rilke, em tradução de Augusto de Campos "De tanto olhar as grades seu olhar/ esmoreceu e nada mais aferra/ Como se houvesse só grades na terra/ grades, apenas grades para olhar// A onda andante e flexível do seu vulto/ em círculos concêntricos decresce/ dança de força em torno a um ponto oculto/ no qual um grande impulso se arrefece". Disponível em: https://ditirambospoesia.wordpress.com/ category/rainer-maria-rilke/ Acesso em: 29/07/2016. 


\section{Referências}

Ancet, Jacques. 1977. Entretien avec Henri Meschonnic. Prétexte, n.12: 63-73.

BAKHTIN, Mikhail (V.N. VOLOCHINOV). 1995 [1929]. Marxismo e filosofia da linguagem. São Paulo: Hucitec.

BAKHTIN, Mikhail. 1997. Estética da criação verbal. São Paulo: Martins Fontes.

BALTAR, Marcos et alii. 2006. Circuito de gêneros: atividades significativas de linguagem para o desenvolvimento da competência discursiva. Linguagem em (Dis)curso. Tubarão, v. 6, n. 3: 375-387.

Bazerman, Charles. 2005. Gêneros textuais, tipificação e interação. São Paulo: Cortez.

Benveniste, Émile. 1976a. A noção de ritmo na sua expressão linguística. In: Problemas de Linguística Geral. São Paulo: Nacional/Edusp. . 1976b. O aparelho formal da enunciação. In: Problemas de Linguística Geral. São Paulo: Nacional/Edusp.

CAmpos, Haroldo. Metalinguagem e outras metas. São Paulo: Perspectiva, 1992.

DeRridA, Jacques. 2001. O monolinguismo do outro - Ou a prótese da origem. Porto: Campo das Letras.

Fairclough, Norman. 2001. Discurso e Mudança Social. Brasília: Editora da UNB.

Goffman, Erving. 1996. A Representação do Eu na Vida Cotidiana. Petrópolis: Vozes.

JAKOBSON, Roman. 1969. Aspectos linguísticos da tradução. In: Linguística e comunicação. São Paulo: Cultrix.

JURADO FILHO, Lourenço Chacon. 1996. Ritmo da escrita: uma organização do heterogêneo da linguagem. Tese de doutorado, IEL/Unicamp. Campinas, SP.

LeA, Mary R.; Street, Brian. 2006. The "Academic Literacies" model: theory and applications. Theory into Practice, 45 (4), 368-377.

LeONTIEV, A. A. 1975. The heuristic principle in the perception, emergence, and assimilation of speech. In: LenNeberg, E. H. \& LenNeBerg, E. (ed.). Foundations of language development: a multidisciplinary approach. New York: Academic Press.

Lotman, Juri. 1998. La Semiosfera II. Semiótica de la cultura, del texto, de la conducta y del espacio. Madrid: Ediciones Cátedra. 2005. On the semiosphere. Sign Systems Studies. 33.1.

Marcuschi, Luiz Antônio. 2001. Da fala para a escrita: atividades de retextualização. São Paulo: Cortez. 
Martins, Maria Sílvia Cintra. 2004. A adoção do método inverso na compreensão da linguagem escrita. $C D-R O M d a 27^{\circ}$ Reunião Anual da ANPED. Caxambu. Versão on-line disponível no site www.anped. org.br/27ra.htm. GT 10 - Alfabetização, leitura e escrita.

2007. Ethos, gêneros e questões identitárias. Revista Delta. São Paulo: EDUC, volume 23, 1, p. 27-43.

. 2010. Ethos e estilo em textos produzidos na esfera acadêmica.

In: SeRrani, Silvana (org.). Letramento, Discurso e Trabalho Docente: uma homenagem a Angela Kleiman. São Paulo: Ed. Hedra/Ecidade.

. 2011a. Letramento, etnicidade e diálogo intercultural. Revista Delta. São Paulo: EDUC, vol.27, n.1, p. 77-98.

.2011b. Aspectos tradutórios do letramento: a construção do estilo.

Linguasagem, no. 18. São Carlos. Disponível em: http://www.letras. ufscar.br/linguasagem/edicao18/artigos/023.pdf

.2014. Letramento e Identidade: as fronteiras da tradução. Revista Scripta vol.32. Belo Horizonte.

Meschonnic, Henri. 1970. Les cinq rouleaux. Paris: Gallimard.

1973. Pour la poétique II. Épistemologie de la écriture. Poétique de la traduction. Paris: Gallimard.

1982. Critique du rithme: anthropologie historique du language. Paris: Verdier. 1995. Politique du rythme. Politique du sujet. Lagrasse: Verdier. 2008. Si la théorie du rythme change toute la théorie du langage change. In: Dans le bois de la langue. Paris: Laurence Teper. . 2010. Traduzir: escrever ou desescrever? Scientia Traductionis, n.7. [Artigo publicado originalmente em Atelier de Traduction: Pour une Poétique du Texte Traduit, 2007].

Ottoni, Paulo (org.). 1998. Tradução: a prática da diferença. CampinasSP, Editora da Unicamp - FAPESP.

PAJEvic, Marko. 2014. Poetic Thinking: A Manifesto for the Humanities as Disciplines of Meaning. Centre for Humanities Innovation. Durham University. Disponível em: https://www.dur.ac.uk/chi/tasks/14/

PAz, Octávio. 2006. Tradução: Literatura e Literariedade. Viva Voz. Belo Horizonte: FALE/UFMG.

Rojo, Roxane; Schneuwly, Bernard. 2006. As relações oral/escrita nos gêneros orais formais e públicos: o caso da conferência acadêmica. Linguagem em (Dis)curso - Tubarão, v. 6, n. 3:463-493, set./dez.

Sсотт, Clive. 2012. Literary translation and the rediscovery of reading. Cambridge: Cambridge University Press.

Vygotski, Lev Semenovich. 1991. Obras escogidas, t.1. Madri: Visor e MEC. 